Classification

Physics Abstracts

07.60P

\title{
Near field optical microscopy by local perturbation of a diffraction spot
}

\author{
Renaud Bachelot, Philippe Gleyzes and Albert Claude Boccara \\ E.S.P.C.I. Laboratoire d'Optique Physique, CNRS UPR A0005, 10, rue Vauquelin, 75005 Paris, France
}

(Received July 4; accepted October 26, 1994)

\begin{abstract}
Résumé. - En utilisant une pointe métallique qui vibre verticalement au dessus de la surface de l'échantillon, et perturbe périodiquement et localement la distribution du champ électromagnétique issu d'un objectif de microscope à grande ouverture numérique, nous avons observé une nette amélioration de la résolution optique, classiquement limitée par la diffraction. Le mouvement de la pointe oscillante est contrôlé par l'interaction répulsive avec la surface de l'échantillon, le déplacement de cette pointe nous fournit un signal de force atomique. Ce microscope optique en champ proche est ainsi couplé à un microscope à force atomique fonctionnant en mode "tapping". Nous décrivons précisément le principe et le montage expérimental, et présentons des images NFOM et AFM d'échantillons dont les caractéristiques optiques et topographiques sont connues.
\end{abstract}

\begin{abstract}
Using a vibrating metallic tip, which periodically and locally modifies the distribution of a converging electromagnetic field issued from a microscope objective, we have observed a clear improvement of the optical resolution compared to the diffraction limited one. This NFOM technique is coupled with a "tapping mode" AFM which uses the same tip. The experimental set-up is described and NFOM and AFM images of known samples are presented.
\end{abstract}

\section{Introduction.}

Since the introduction of local probe microscopy, such as Scanning Tunnelling Microscopy [1], Atomic Force Microscopy [2], a large variety of new techniques have been invented or revisited. Among them, Near Field Optical Microscopy (NFOM) has successfully demonstrated its ability to break the resolution limit imposed by the diffraction $[3,4]$.

In the more classical realisation of the microscope, the electromagnetic radiation (wavelength $\lambda$ ) is confined within a cone and irradiates the sample under examination through a small aperture (diameter $\ll \lambda$ ) close to its surface (distance $\ll \lambda$ ). The image is obtained by scanning this small source along the sample surface and by collecting the reflected or transmitted energy. We would like to present here an alternative way of achieving a local selection of a field distribution much smaller than $\lambda$ by using a metallic vibrating tip on the top of a surface irradiated by a strongly converging beam. 


\section{Principle (Fig. 1).}

The main idea is to use the periodic vibration of a metallic apertureless tip above a diffraction spot of a laser beam, which passes through a microscope objective and is focused onto the sample.

The tip, whose point has been reduced to about $100 \mathrm{~nm}$, vibrates perpendicular to the sample surface with an amplitude of $50 \mathrm{~nm}$.

During a vibration period, at the top of its trajectory, the tip is $100 \mathrm{~nm}$ away from the sample and it slightly perturbs the light field on the sample. At the bottom of its trajectory, the tip is very near to the sample and generates a much larger and more local perturbation of the field, cancelling it out on a sub-micronic area of the sample. In a way, the tip periodically prevents the light field from reaching a specific portion of the sample which alternately takes part or not in the detected reflected light.

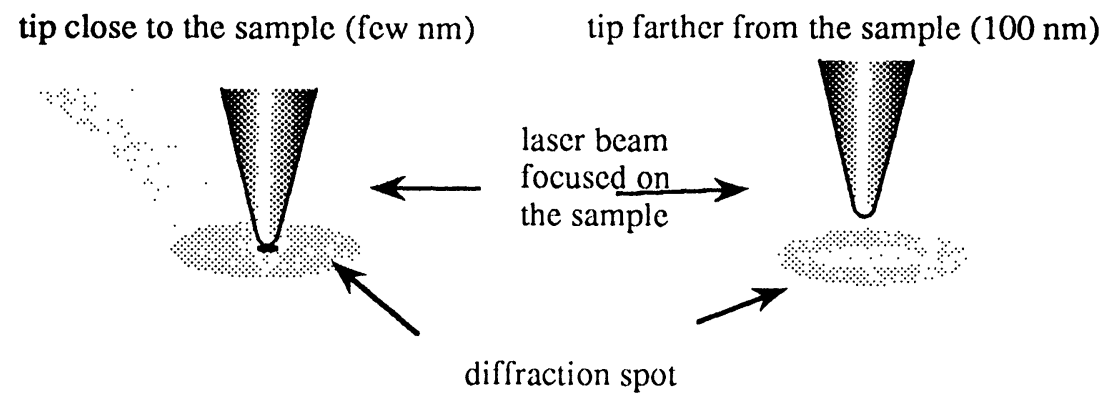

Fig. 1. - Oscillating tip (diameter $\sim 0.1 \mu \mathrm{m}$ ) near the sample surface in presence of the converging beam issued from the microscope objective (diameter $\sim 1 \mu \mathrm{m}$ ).

This perspective might appear a bit naive. Nevertheless, it was confirmed by a scalar field calculation that we have performed [5]. In this way, the reflected detected optical signal has two components; a continuous one which represents the far field and is associated with the laser spot diameter (about 1 micron), and a "near field" alternating one which we require to be sensitive, during scanning, to spatial variations of the optical reflection coefficient of the sample with a submicronic lateral resolution.

\section{Description of the set-up (Fig. 2a).}

Our experimental set-up has been built below a commercial microscope (Olympus BHMJ) equipped with a long working distance $X 50$ objective allowing the focus of a laser diode $(\lambda=670 \mathrm{~nm})$ onto the sample surface through the "photographic output" and the simultaneous observation of the working field (laser diode spot, tip and sample surface). The tip is a tungsten cone whose point has been reduced to about $100 \mathrm{~nm}$ (Micro Probe Inc.) (Fig. 3), bent and attached to a PZT ceramic which excites it at its resonant frequency (about $4 \mathrm{KHz}$ ). The $\mathrm{k}$ force constant of this cantilever is a few $\mathrm{N} / \mathrm{m}$. The amplitude of vibration is measured by transverse probe beam focused on the lever arm, which acts like a knife edge, and lock-in detected by a photodiode (PD2) (Fig. 2b).

The vibrating tip is moved near to the sample. When it reaches the surface, its vibration amplitude suddenly decreases and becomes proportional with the tip-sample distance. In fact, the tip 


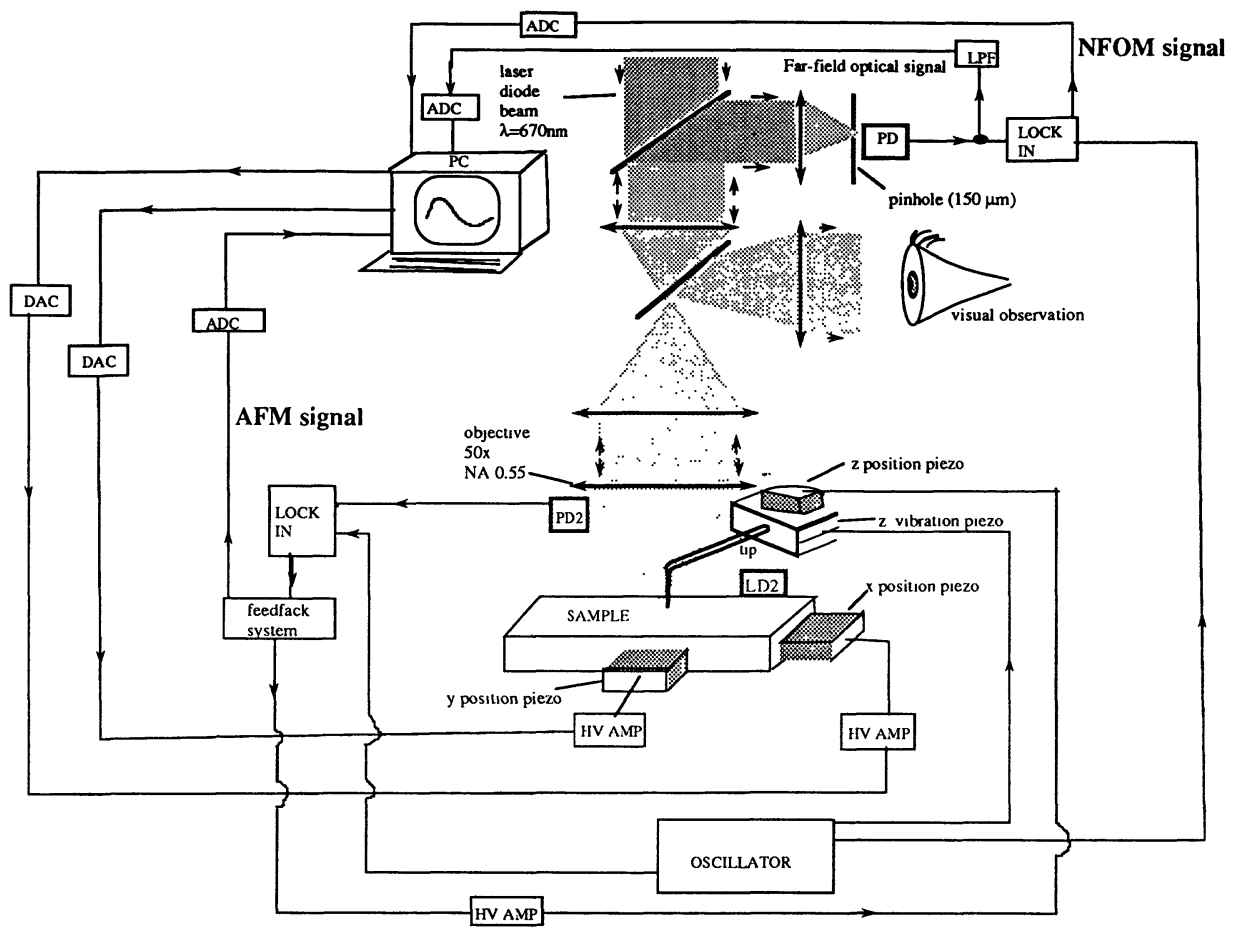

Fig. 2a. - Diagram of the experimental set-up, LD, Laser Diode; PD, Photodiode; DAC, Digital-Analogic Convertor; ADC, Analogic-Digital Convertor; LPF, Low-Pass Filter.

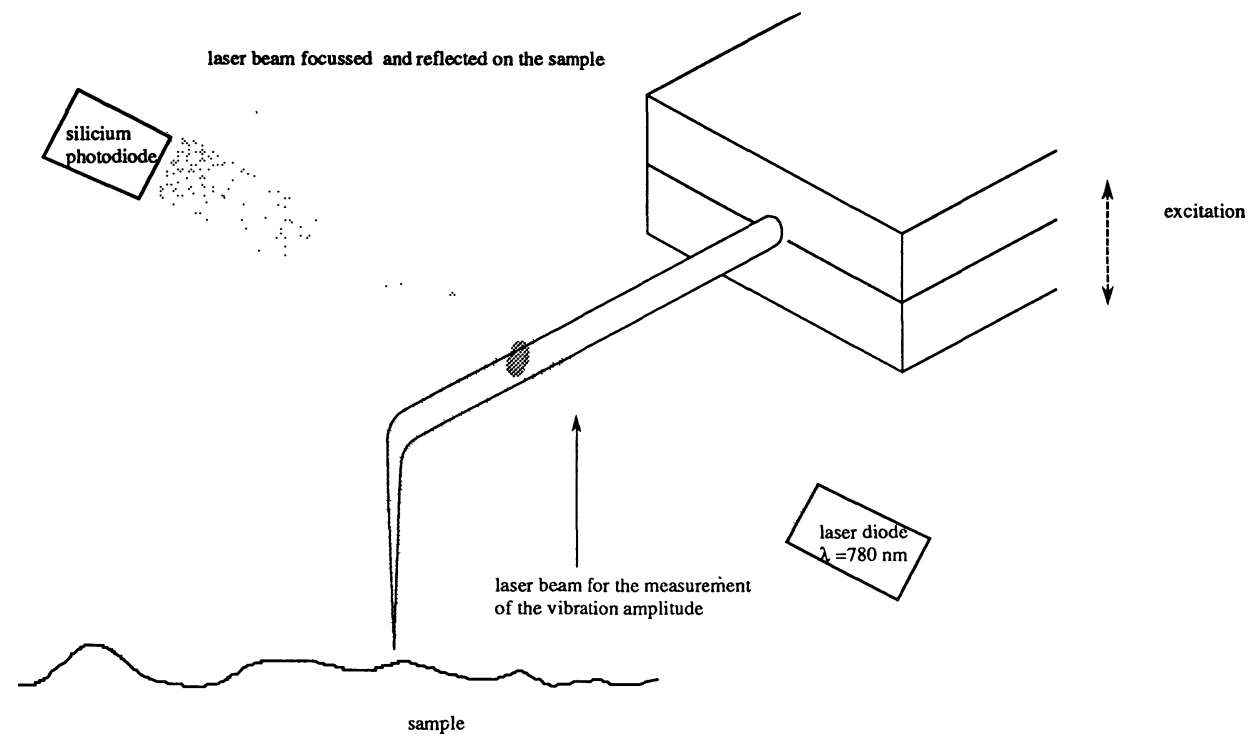

Fig. 2b. - Experimental detection of the tip motion.

periodically crosses the adhesion force layer (the stiffness constant $\mathrm{k}$ and the vibration amplitude are large enough) and "taps" within the repulsive atomic force field of the sample. Numerical and 


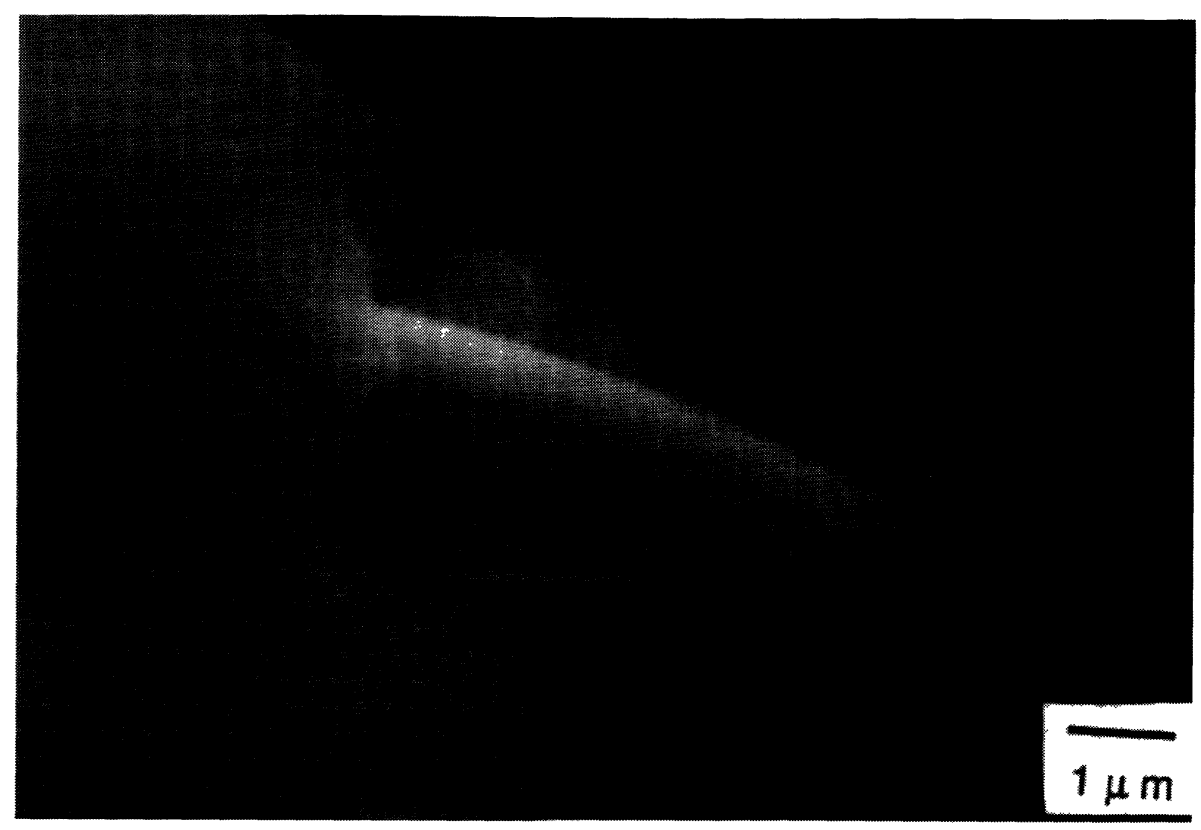

Fig. 3. - SEM image of the MICRO-PROBE Inc. tungsten tip. In this picture, the tip body is coated by perylen insulation. For our experiments, we order and use uninsulated tips.
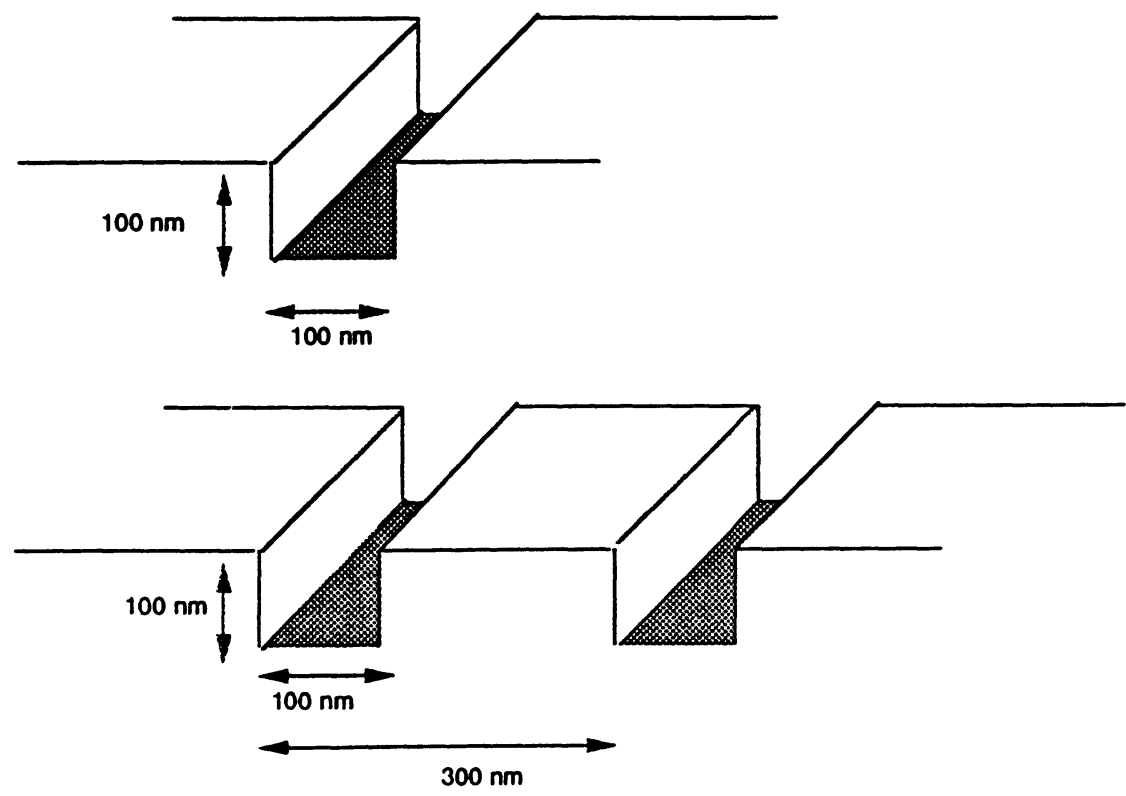

Fig. 4. - Test samples; 1 or 2 grooves engraved by X-ray lithography. At the bottom of each groove (Si), the optical reflection coefficient is smaller than that of the surronding one (Au). 
analytic model of the motion of the tip vibrating close to the surface has allowed us to understand and interpret most of the behaviour of the tip in interaction with the repulsive force field [6] (recently, we have extended this theorical work taking into account both the attractive and repulsive force field)

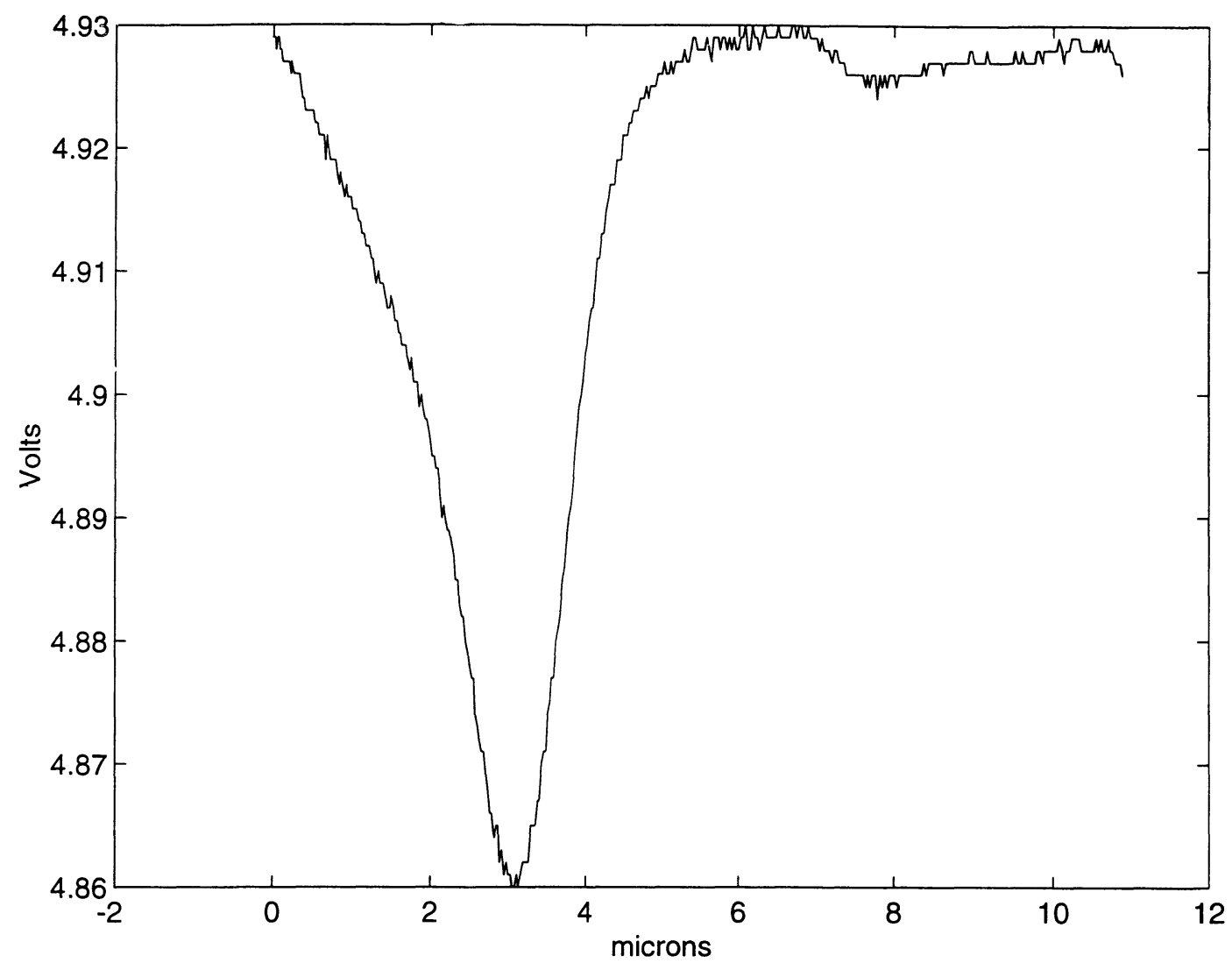

Fig. 5. - Far-field optical linear profile of a groove.

This "tapping mode" presents several advantages. First, it allows the tip to have the motion described above, in the principle (notably, we are sure that, at the bottom of its trajectory, the tipsample distance is very small). Second, this distance-amplitude dependency allows, by a feedback loop, to keep the amplitude (so the distance) at a constant value during scanning, allowing the optical signal to avoid the influence of the topography, and avoiding damage to the tip and sample. Finally, the output signal of this loop provides a topographic image of the sample. The reflected light field passes through the microscope, is selected by a $150 \mu \mathrm{m}$ pinhole in the image plane and detected by a photodiode. Lock-in detection provides the NFOM alternating signal (amplitude and phase), and direct detection with low pass filter provides the continuous far-field optical signal.

In a preliminary version of the set-up [7], we have demonstrated an improvement in the resolution which has been revealed by the gain in contrast when observing a periodic structure. In our new set-up, we have replaced the mechanical scanning of the sample $(0.1 \mu \mathrm{m}$ resolution $)$ by a 
a)

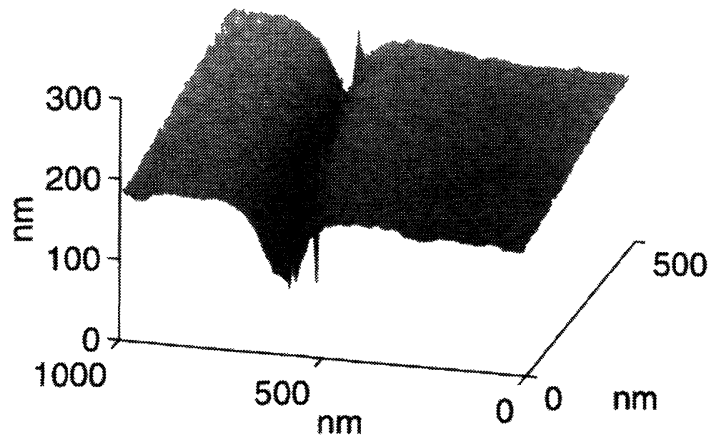

c)

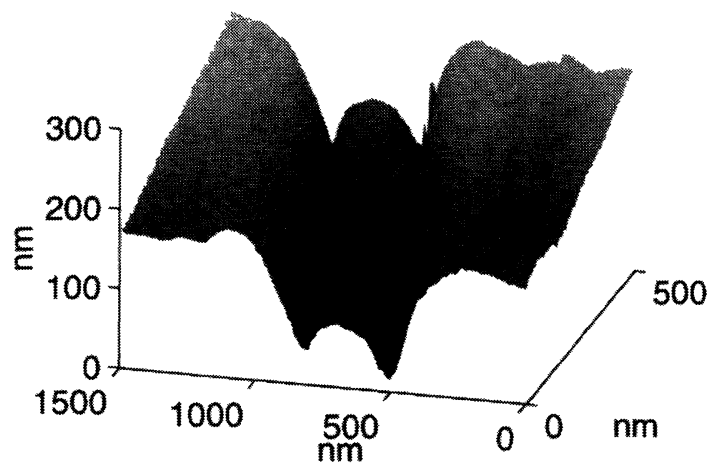

b)

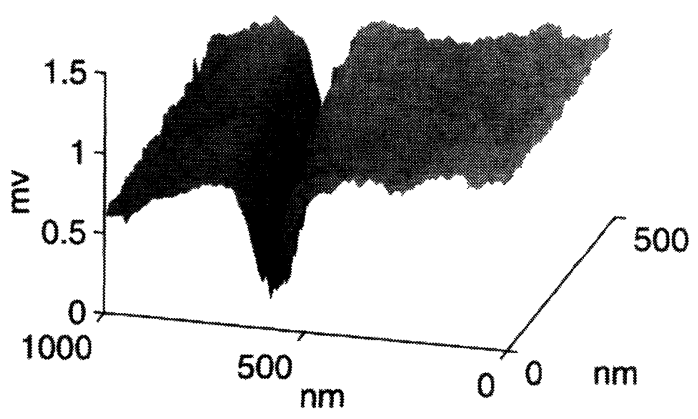

d)

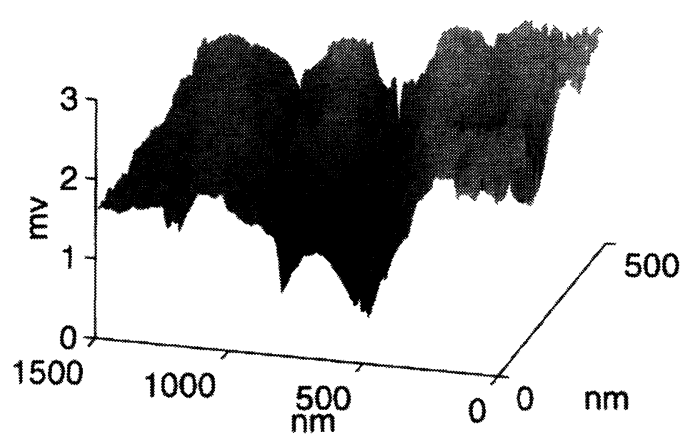

Fig. 6. - Images of the test sample. One groove: relief a), NFOM (amplitude) b). Two grooves: relief c), NFOM (amplitude) d).

PZT scanning coupled with an heterodyne interferometer $(0.01 \mu \mathrm{m}$ resolution $)$ which allow us to study structural details on the nm scale.

\section{Results and discussions.}

To show the optical resolution improvement, we have studied a test sample whose topographic and optical properties are known. It is made up of several micro structures prepared by X-ray lithography. In particular, we have studied two kinds of structures: a single groove, $100 \mathrm{~nm}$ wide and $100 \mathrm{~nm}$ deep; and two grooves, each $100 \mathrm{~nm}$ wide, $100 \mathrm{~nm}$ deep, and $300 \mathrm{~nm}$ separated (Fig. 4). Each groove has an optical reflection coefficient $(\mathrm{Si})$ smaller than that of the surrounding one (Au).

Figure 5 shows the continuous optical far field signal when scanning a $100 \mathrm{~nm}$ groove. The half-height band width is about $1.5 \mu \mathrm{m}$ which is the diameter of the diffraction spot. The optical lateral resolution is limited by diffraction and the real optical characteristics are lost.

Figure 6 shows the measured $1 \times 0.5 \mu \mathrm{m}^{2}$ and $1.5 \times 0.5 \mu \mathrm{m}^{2} \mathrm{NFOM}$ and AFM images of the sample. The expected geometric (depth, width) and optical characteristic are obtained. The 
a)

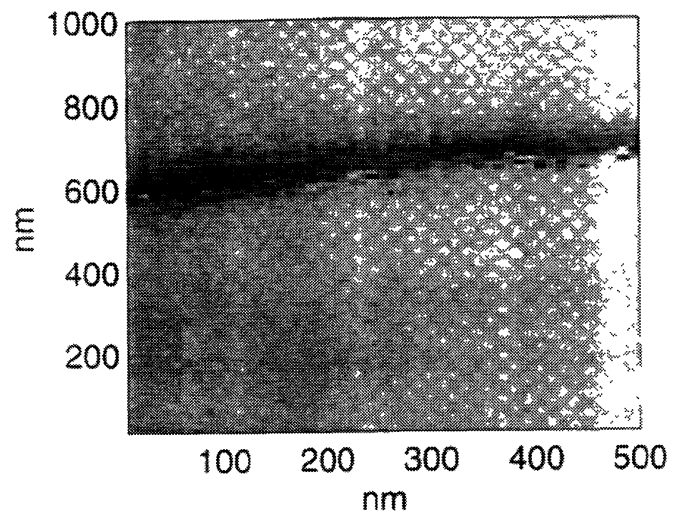

c)

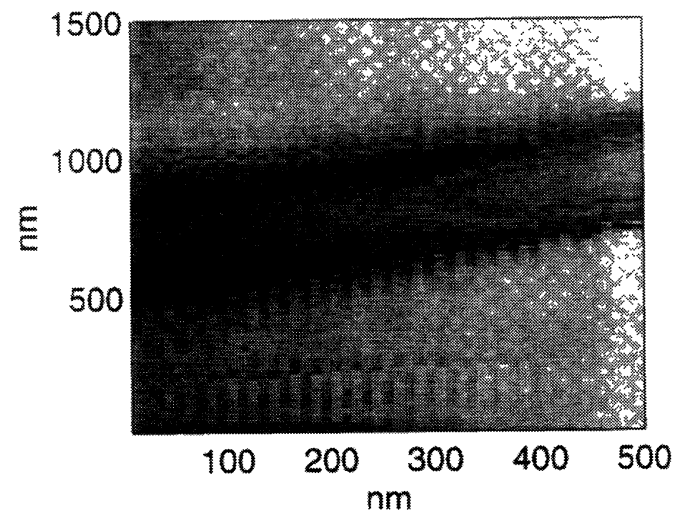

b)

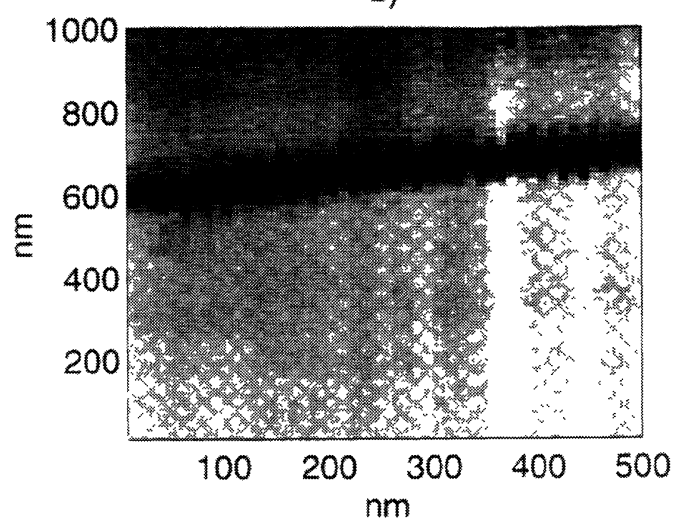

d)

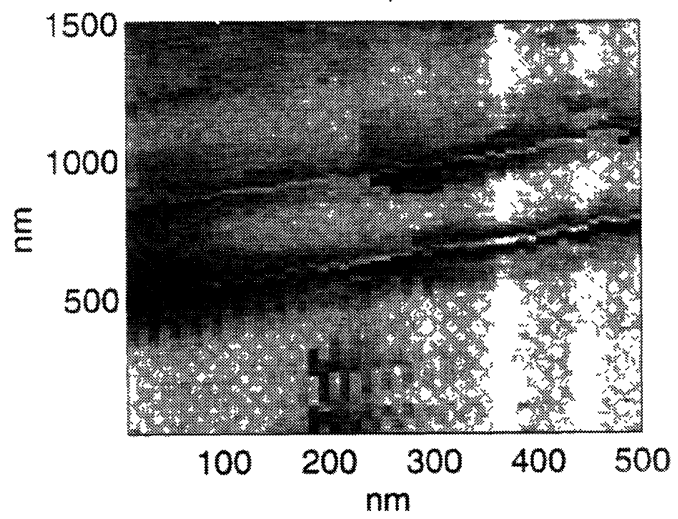

Fig. 7. - Topview images of the test sample. One groove: relief a), NFOM (amplitude) b). Two grooves: relief c), NFOM (amplitude) d).

apparent triangular shape of the grooves is due to the shape of the tip and the convolution between the $100 \mathrm{~nm}$ probe tip and the $100 \mathrm{~nm}$ structure. Figure 7 is a topview of the same image. It shows the $100 \mathrm{~nm}$ width and the $300 \mathrm{~nm}$ separation of the grooves, as well as the perfect correlation between the AFM and NFOM images. The resolution in the optical image is comparable with the AFM image: $100 \mathrm{~nm}$.

Figure 8 represents the NFOM signal when scanning a groove at various tip-sample distances, $1.4,1,0.7,0.5 \mu \mathrm{m}$ (the tip doesn't tap on the sample), and $0 \mu \mathrm{m}$ (the tip taps on the sample). We note that the obtained half-height band widths of these optical profiles are respectively about 1.3 , $0.9,0.7,0.5,0.1 \mu \mathrm{m}$. This result is in keeping with a known result which is that, in NFOM, the smallest resolvable features are roughly determined by the greater of the probe size and the probe to sample separation [8].

We point out that all these measurements are reproducible and that this technique does not appear to be destructive.

More detailed calculations and specific experiments will give us more information about the respective influence of the local topography and the optical characteristics on the NFOM signal. 
a)

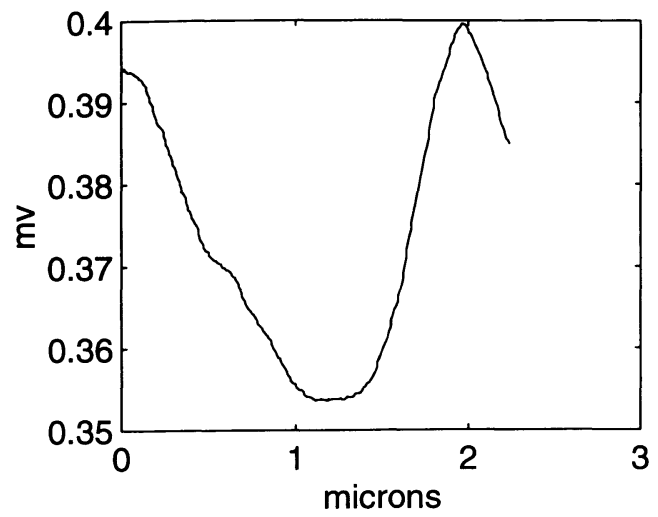

c)

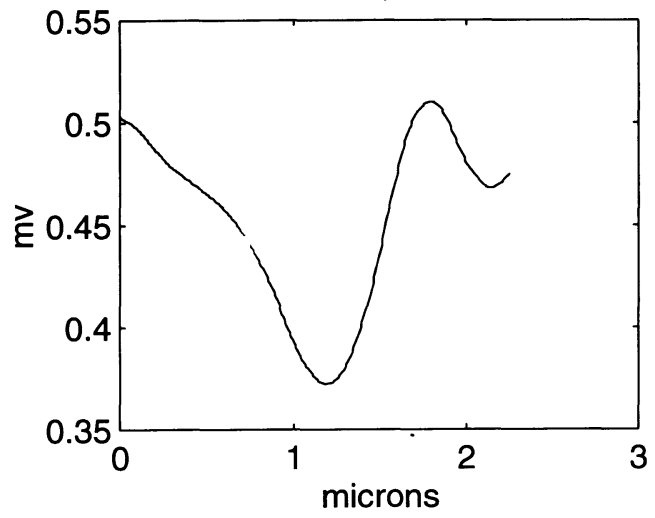

b)

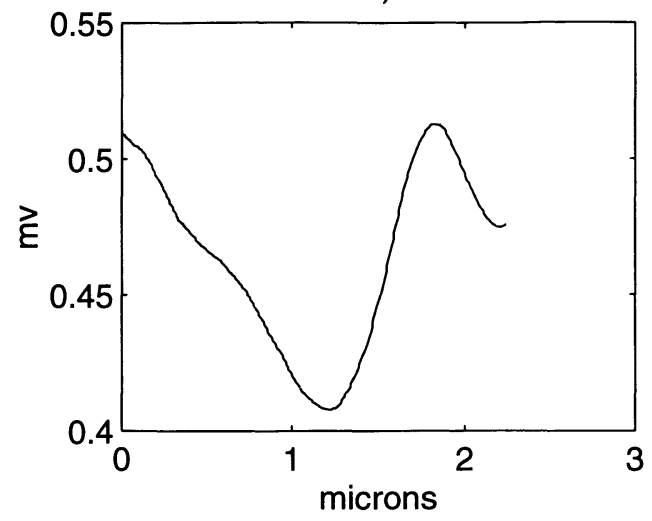

d)

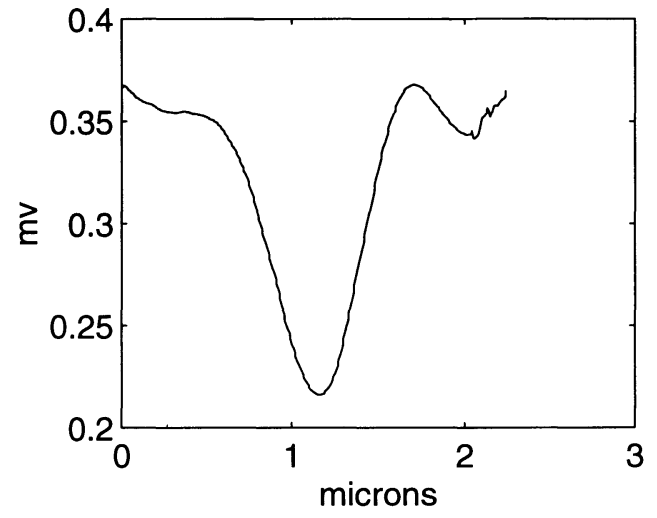

e)

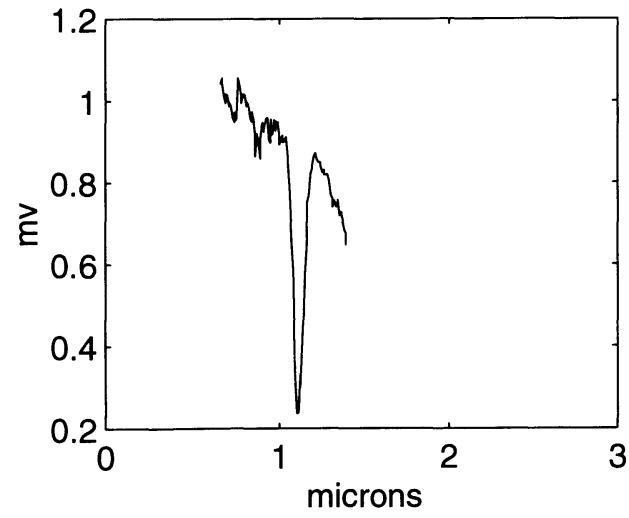

Fig. 8. - NFOM linear profile (amplitude) of a groove at various tip-sample distances; $1.4 \mu \mathrm{m} \mathrm{a}), 1 \mu \mathrm{m} \mathrm{b}$ ), $0.7 \mu \mathrm{m} \mathrm{c}), 0.5 \mu \mathrm{m} \mathrm{d}), 0 \mu \mathrm{m} \mathrm{e})$.

\section{Conclusion and perspectives.}

This combinaison of a NFOM with a "tapping mode" AFM has allowed us to reach a $100 \mathrm{~nm}$ optical lateral resolution. This resolution is still modest $(\lambda / 7)$ but it is only limited by the probe size. 
At present, there is an uncertainty about the interpretation of the NFOM images. Soon, several measurements with "flat" samples having optical contrasts will show specifically the influence of the local optical properties of the sample on the NFOM signal. In addition, to improve the resolution, we are going to test tungsten tips which we produce by electrochemical techniques [9] and whose point are about $20 \mathrm{~nm}$ size.

\section{Acknowledgements.}

The authors would like to thank H. Launois (Ultimatech) for encouragement and financial support, M.Y. Chen for the samples and helpful discussion, and M. Dubon for the electron microscope images of the probe tip.

\section{References}

[1] Binning C., Rohrer H., Gerber Ch and Weibel E., Phys. Rev. Lett. 49 (1982) 57.

[2] Binning C. and Quate H., Phys. Lett. 56 (1986) 930.

[3] Pohl D.W., Denk W. and Lanz M., Appl. Phys. Lett. 44 (1984) 651.

[4] Proceeding of the Workshop on Near Field Optics, Arc et Senans, october 1992, Pohl and Courjon Eds. (NATO ASI series, 1993).

[5] Philippe GLEYZES's thesis (PARIS XI), “Contribution à, l'amélioration de la résolution en microscopie optique : profilométrie différentielle picométrique et imagerie en champ proche" (June 1993).

[6] Gleyzes P., Kuo P. K. and Boccara A. C., Appl. Phys. Lett. 58 (1991) 2989.

[7] Gleyzes P., Boccara A.C. and Bachelot R., Second International Conference on Near Field Optics (Rayleigh, october 1994) To be published by Ultramicroscopy.

[8] Betzig E., Isaacson M. and Lewis A., Appl. Phys. Lett. 51 (1987) 2088.

[9] Lemke H., Goddenheinrich T., Bochem H.P., Hartmann U. and Heiden C., Rev. Sci. Instrum. 61 (1990) 10. 